\title{
Genetic Evaluation of Murrah Buffaloes for Reproductive Disorders
}

\author{
Palpreet Singh ${ }^{1}$, Simrinder Singh Sodhi ${ }^{2 *}$, Shakti Kant Dash ${ }^{1}$, Shahbaz Singh Dhindsa ${ }^{3}$, \\ Simarjeet Kaur ${ }^{1}$ and Puneet Malhotra ${ }^{1}$ \\ ${ }^{1}$ Department of Animal Genetics and Breeding, College of Veterinary Science, GADVASU, Ludhiana, INDIA \\ ${ }^{2}$ School of Animal Biotechnology, GADVASU, Ludhiana, INDIA \\ ${ }^{3}$ Department of Veterinary Gynaecology and Obstetrics, GADVASU, Ludhiana, INDIA \\ *Corresponding author: SS Sodhi; E-mail: simrindersodhi@gmail.com
}

Received: 15 Nov., 2019

Revised: 27 Nov., 2019

Accepted: 30 Nov., 2019

\begin{abstract}
The present investigation was carried out on 459 Murrah buffaloes affected with some reproductive problem with 618 calving records(out of total 1336 Murrah buffaloes) sired by 118 sires over a period of 12 years from 2007 to 2018 at GADVASU, Ludhiana. The heritability estimates for dystocia, retention of placenta (ROP), anestrus, repeat breeding (RB), abortion and postpartum abnormal discharge (PPAD) were $0.04,0.10,0.05,0.074,0.085$ and 0.121 respectively. The overall means for breeding values for dystocia, ROP, abortion, anestrus, RB and PPAD were 0.4, 0.2, 0.4, 0.2, 0.078 and 11.8\%, respectively. Rank correlation of abortion with ROP was very high $(0.99 \pm 0.02)$ and with anestrus, dystocia, RB and PPAD were also high i.e. $0.98 \pm 0.03,0.98 \pm 0.03,0.97 \pm 0.03,0.95 \pm 0.04$ respectively. Heritability estimates of reproductive problems have indicated appreciable values, signifying that incorporation of these traits in selection program will enhance the rate of improvement.
\end{abstract}

Keywords: Murrah Buffalo, Threshold traits, reproductive disorders, Heritability, Breeding value

India is predominantly an agricultural country with $70 \%$ of the population depend upon agriculture and rearing of livestock. The vastness of an Indian dairying may also be attributed to the fact that India possesses the largest bovine population of 299.6 million which comprises of 190.9 million cattle and 108.7 million buffaloes (DADHF, 2012). The total livestock population has decreased by about $3.33 \%$ but livestock population has increased in Punjab by $9.57 \%$ (DADHF, 2012). The share of Gross Value Added of livestock sector to the Agriculture Sector (Crops, Forestry, Livestock and Fishing) has increased from $21.8 \%$ in $2011-12$ to $25.8 \%$ in $2015-16$ and livestock sector contributes $4.5 \%$ of total GVA (DADHF, 2017).

Buffaloes are known as Indian milking machine. The superiority of buffalo over local cow with regard to milk production is widely accepted in India. Indians have preference for buffalo over cattle because of their distinctive qualiyies such as better feed conversion efficiency, more resistance to diseases and higher milk fat percentage and it is for this reason that the population of buffaloes is increasing day by day (Singh, 2015). However, there appears to be an international resistance by the dairy exporting countries to create a worldwide prebiased attitude against the products manufactured from buffalo milk. Therefore it is high time for India to stalwartly rebut this false notion against buffalo milk and highlight its positive attributes at the international forum. Inspite of buffaloes significant role as a milk producer, it did not find its desired place in scientific literature, especially w.r.t. health and survivability information coupled with specific reference to the role of inheritance. The accredited advantages of the buffalo are fully appreciated only by the persons who keep buffaloes for their livelihood.

Buffaloes contribute about fifty percent of the total milk production of our country though contributing to only

How to cite this article: Singh, P., Sodhi, S.S., Dash, S.K., Dhindsa, S.S. Kaur, S. and Malhotra, P. (2019). Genetic evaluation of murrah buffaloes for reproductive disorders. J. Anim. Res., 9(6): 807-814. 
one-third of the total bovine population (DADHF, 2012). India is fortunate enough to have the world's best breeds of buffaloes. Special attention has to be made to Murrah breed of buffaloes, which is one of the best breed of buffaloes and can be considered as black diamond or Holstein-Friesian of the buffalo world (Singh, 2015) and it contributes $44.39 \%$ of total buffalo population (DADHF, 2017). Avoidably of superior germplasm of Murrah buffaloes in India gives us an opportunity to help other buffalo breeding countries in breed improvement programmes by shipping frozen semen to their destination. Therefore, all the countries of the world look forward to India for improvement of their native poor quality buffalo breeds. Hence, there is a dire need that we should exploit our high quality Murrah buffaloes for further improvement of their performance. Inspite of its unique ability to make ends meet under harsh condition, the buffaloes have been neglected by breeders and research scientists. Buffaloes are reputed as an efficient converter of low grade, fibrous feeds into high value milk, containing 7 percent fat, which is almost twice as that of cow milk (Taraphder, 2002). To make dairying a successful and profitable business, buffaloes should not only be the high producer but also be healthy, disease free and regular breeder. A low incidence of disease, mortality, and regular breeding may help to increase the selection differential thereby genetic improvement.

Losses due to diseases i.e. losses due to mortality, reduced production, cost of treatment and reduced consumers preference have a remarkable impact on the dairy industry. Culling of buffaloes because of reproductive problems accounts for a great loss of milk production as well as offspring (Taraphder, 2002). Reproductive disorders and lower fertility condenses the income to dairy farmer by decreasing milk yield and reproduction. Further high veterinary expenses in addition to reduction in longevity of buffaloes also create burden.

Among the reproductive disorders, repeat breeding (RB), anestrus, retention of fetal membranes, and abortion are the most important livestock maladies affecting a variety of livestock species including cattle and buffaloes. The reproductive disorders affect the dairy industry with profound economic loss and trade impact in India (Khan et al., 2011). Whenever possible, the diseases of livestock should be avoided by use of prophylactic measures like immunization, sanitation, management and removal of stresses. Those diseases which are not responsive to preventive measures and are inherited could be controlled through the development of genetically resistant animals. Studies on disease resistance have been mainly conducted in the field of plant breeding and consequently genetically resistant varieties to various plant pathogens have been evolved (Taraphder, 2002). The information on the incidence and inheritance of diseases and mortality in dairy cattle of advanced countries is well documented, but such estimates are scanty for Indian breeds of cattle and especially buffaloes.

Majority of the animals would respond to genetic selection for resistance to disease because the genetic merit of the population for a certain trait can be changed through selection and breeding programme. Such process requires the estimation of genetic variability present for a trait. There is an evidence that the life span is determined by heredity and there also exists genetic variability for resistance to diseases (Hut, 1958). It provides a means for improving the response to selection which can be utilized for disease resistance and longer life span.

The information on the incidence and inheritance of reproductive disorders in buffaloes are scanty and probably no information is available. Meager reports are available regarding the economic aspects (expenditure or cost involved in treatment) as well as the estimates of breeding value for reproductive disorders and construction of selection indices incorporating the important reproductive disorders.

Therefore, there is a dire need to find out the role of inheritance of reproductive disorders in genetic improvement programme of Murrah buffaloes. Keeping in view the above aspects, the present study was envisaged to investigate the inheritance of reproductive disorders in the Murrah buffalo herd maintained at dairy farm, Guru Angad Dev Veterinary and Animal Sciences (GADVASU), Ludhiana.

\section{MATERIALS AND METHODS}

\section{Location}

The present study was carried out on Murrah buffalo herd maintained at the dairy farm of the Directorate of Livestock Farms (DLF), GADVASU, Ludhiana. 


\section{Source of data}

The data pertaining to the reproductive problems of Murrah buffaloes were collected from the records and history sheets maintained at DLF, GADVASU, Ludhiana.

\section{Management and feeding of herd}

The animals were kept in loose housing system with one third shaded area at the dairy farm. Ad-libitum feeding and free access to water was practiced. The animals were housed separately on the basis of their age and production levels.

The weaning of calves was done immediately after birth and then they were fed on colostrum for first five days and then whole milk from sixth day to sixteen weeks of age.

All the female animals were bred through artificial insemination. Animals in advance stage of pregnancy were segregated to calving pens at least six weeks before the expected date of calving. Body weights were recorded by weighing the animals monthly in the morning before feeding and newly born were weighed before colostrums feeding.

The maintenance and growth ration were fed to the animals in the morning hours once a day and feeding total mixed ration (TMR) was practiced post 2012. While production ration was given to the milking buffaloes at the time of milking. Concentrate ration $(\mathrm{CP}=18 \%$ and $\mathrm{TDN}=$ $70 \%$ ) were formulated using cereals, cakes, brans, mineral mixture, salt and additives depending upon season and physiological status (age, production, stage of pregnancy etc.) of animal.

\section{Information of Murrah buffaloes}

General information e.g. animal number, dam number, sire number, date of successful service, total number of artificial insemination done, date of calving (upto $6^{\text {th }}$ calving), types of calving in each lactation (upto $6^{\text {th }}$ calving) and parity number (upto $6^{\text {th }}$ parity) was collected for the identification and classification of Murrah buffaloes.

\section{Information regarding reproductive disorders}

The information pertaining to reproductive disorders since January 2007 to December 2018, recorded on the
Murrah buffaloes of the herd maintained at GADVASU was compiled. The various reproductive disorders to be incorporated in the current study were divided into two main categories i.e. periparturient complications which included dystocia, still birth (SB),premature birth and retention of placenta (ROP) and successively other reproductive problems such as anestrus, repeat breeding (RB), prolapse, postpartum abnormal discharge (PPAD) and abortion.

\section{Data structure}

The data on reproductive disorders were collected from the records maintained at dairy farm GADVASU, Ludhiana. Data comprised of records on calving, reproductive performance and reproductive disorders. The study included 618 calving records of 459 Murrah buffaloes (affected with any of the reproductive disorders mentioned above), from total of 1336 Murrah buffaloes.

The records of Murrah buffalo with known pedigree were used for analysis of reproductive disorders. Animals with improper records were not included in the study.

\section{Classification of non-genetic factors}

Non-genetic factors viz. Parity, Period and Season of calving were classified into subclasses to assess the effect of non-genetic factors on different reproductive traits.

\section{Parity}

Parities were taken into consideration upto recent lactation recorded in the available reproduction sheets of the herd. The data were classified for different parities upto sixth parity and each parity was coded starting from code " 1 " to code "6" upto sixth parity.

\section{Period of calving}

The data on reproductive disorders from a span of 12 years were classified into 4 periods with each period covering 3 years of duration (Table 1).

\section{Season of calving}

The months of an year were grouped into 4 seasons on the basis of prevailing climatic conditions of Punjab. 
December to February, had been classified as Winter season, followed by March to May as Summer season. The Rainy season had be regarded as from months June to August whereas the following months from September to November were classified as Autumn season.

\section{STATISTICAL ANALYSIS}

For statistical analysis of the data, Statistical analysis system software programme (SAS, 2011) version 9.3 was used. The means, standard deviations, standard error were estimated by using standard statistical procedures.

\section{Estimation of heritability}

Robertson and Lerner (1949) estimated the heritability as the ratio of selection response to selection differential which is regression of genotype on phenotype. The genotypic values for viability of the members in terms of the probabilities of survival of the corresponding genotype under the given array of environmental conditions are taken as $\mathrm{P} 1, \mathrm{P} 2 \ldots \ldots . . \mathrm{Pn}$ with mean $p$ and the variance $\sigma^{2}{ }_{P}$. The expectation for the gain is $\sigma^{2} / \mathrm{P}$. The phenotypic selection differential is $1-p$ which is the difference between the phenotype of survivors (taken as unity) and the mean phenotype of the population. Therefore heritability is taken as:

$$
h^{2}=\frac{\text { Genetic gain }}{\text { Selection differential }}=\frac{\sigma_{A}^{2}}{\bar{P}(1-\bar{P})}
$$

Where,

$\sigma_{P}^{2}$ is the genetic variance and estimated as:

$$
\sigma_{A}^{2}=\frac{\left[\Sigma \frac{a_{i}^{2}}{n_{i}}-\frac{\left(\Sigma a_{i}\right)^{2}}{\Sigma n_{i}}\right]-(N-1) \bar{p}(1-\bar{p})}{r n_{0}}
$$

$\sum_{i=1}^{N} \frac{a_{i}^{2}}{n_{i}}-\frac{\left(\Sigma a_{i}\right)^{2}}{\Sigma n_{i}}=$ Sum of squares between classes

With N-1 Degree of freedom

The expected value of this sum of squares is

$$
(N-1)(\bar{P})(1-\bar{P})+r n_{0} \sigma \frac{2}{p}
$$

Where,

$r=$ difference in genetic relationship between and within classes or the genetic relationship between the members of a sire family.

$r=1 / 2$ for full sibs and $1 / 4$ for half sibs

$$
n_{0}=\Sigma n_{i}-\frac{\Sigma n_{i}^{2}}{\Sigma n_{i}}-(N-1)=(K-1)(S-1)
$$

Where,

$$
\begin{gathered}
\mathrm{K}=\frac{1}{S-1}\left[\sum n_{i}-\frac{\Sigma n_{i}^{2}}{\Sigma n_{i}}\right] \\
\mathrm{S}=\text { No. of sires }
\end{gathered}
$$

$\overline{\mathrm{P}}(1-\overline{\mathrm{P}})=$ total variance which is the normal expression for the variance of a binomial population

The heritability equals,

$$
\begin{aligned}
& h^{2}=\frac{\sigma_{A}^{2}}{\bar{p}(1-\bar{p})}=\left[\frac{\sum \frac{a_{i}^{2}}{n_{i}}-\frac{\left(\Sigma a_{i}\right)^{2}}{\Sigma n_{i}}}{\bar{p}(1-\bar{p})}-(N-1)\right] / \\
& r n_{0}=\frac{\chi^{2}-(N-1)}{r n_{0}}
\end{aligned}
$$

$a_{1}$ and $n_{1}=$ number of surviving and total progeny of $i^{\text {th }}$ sire

$N=$ Number of sires

$n=$ number of progeny per sire.

The heterogeneity $\chi$ can be estimated from SX2 contingency table for the data on survival according to sire groups giving the number of survivors and non-survivors for each of S sires.

The analysis of variance can be applied to determine the genetic variance of binominal data. The phenotypic value can be denoted by the model as:

$$
X_{t j}=U+S_{i}+e_{t j}
$$


Where,

$X_{t j}$ is the phenotypic value of the progeny of $i^{\text {th }}$ sire which is a random variable and takes the value 1 if $j^{\text {th }}$ progeny survive and takes the value zero if it dies.

$u$ is the general mean representing overall survival and is taken as fixed effect

$S_{i}$ is the effect of $\mathrm{i}^{\text {th }}$ sire and treated as a random effect with mean zero and variance as $\sigma_{\mathrm{s}}^{2}$

$e_{t j}$ is the random error component for survival of $\mathrm{j}^{\text {th }}$ progeny of $i^{\text {th }}$ sire. It is a binomial variate with parameter $p$ which means that $e_{t j}$ takes value 1 with probability $p$ and takes value with probability $(1-p)$.

Then,

$$
\begin{gathered}
E\left(e_{t j}\right)=1 x p+o x(1-p)=p \\
V\left(e_{t j}\right)=E\left(e_{t j}-p\right) 2 \\
=p-p^{2}=p(1-p)
\end{gathered}
$$

The $s_{1}$ 's are independent. The $e_{t j}$ 's are also independent amongst themselves.

The sire-wise data on progeny for survivability takes the form as given in Table 1

Table 1: Sire-progeny Groups

\begin{tabular}{ccc}
\hline \multirow{2}{*}{ Sire No. } & \multicolumn{2}{c}{ No. of Progenies } \\
\cline { 2 - 3 } & Affected (n) & Non- affected(a) \\
\hline 1 & $\mathrm{n} 1$ & al \\
2 & $\mathrm{n} 2$ &.. \\
. &.. &.. \\
S & $\mathrm{Ns}$ & As \\
\hline Total & $\Sigma n_{i}$ & $\Sigma n_{i}$ \\
\hline
\end{tabular}

With as estimate of the phenotypic value of the overall survival $(\overline{\mathrm{P}})$ as :

$$
\bar{p}=\frac{\sum_{i=j}^{s} a_{i}}{\sum n_{i}}
$$

The phenotypic variance can be divided by ANOVA into observational components attributable to differences between the progeny of different sires $\left(\sigma_{s}^{2}\right)$ and to the same sire (between dams within sire component, $\left(\sigma_{s}^{2}\right)$. The sum of the two is an estimate of the phenotypic variance of the observational components as $\left(\sigma_{s}^{2}\right)+\left(\sigma_{e}^{2}\right)$.

The standard error of $h^{2}$ is $(\sigma / r)$

$$
s_{t}=\frac{1+[(n-1) t](1-t) \sqrt{2}}{\sqrt{n(n-1)(n-2)}}
$$

Where $t$ is the phenotypic correlation between the members of the sire family and equal $r h^{2}$.

\section{Estimation of expected breeding value}

The sires were evaluated by following sire index method on the basis of first lactation performance of daughters for reproductive disorder traits.

The sire index value will be computed as,

Where,

$$
\mathrm{I}=A+\frac{2 n h^{2}}{\left[4+(n-1) h^{2}\right]}\left(S_{i}\right)
$$

$I=$ Sire index

$A=$ Population mean

$n=$ Number of daughters of the sire.

$h^{2}=$ Heritability of trait

$S_{\mathrm{i}}=$ Sire constant for $\mathrm{i}^{\text {th }}$ sire

The percent superiority of the sire indices over the herd average will be calculated for each sire using the following formula:

\section{I-A}

Percent superiority over herd average $=\frac{I-A}{A} \times 100$ Where,

$$
\begin{aligned}
& I=\text { Sire index value } \\
& A=\text { Herd average }
\end{aligned}
$$

The sires were ranked by sire indexing procedure for reproductive disorder traits. The correlations between the ranking of sires based on various traits will be calculated 
by Pearson and Spearman's rank correlation coefficient (Steel and Torrie, 1960).

\section{RESULTS AND DISCUSSION}

\section{Heritability}

Heritability of a trait gives an idea of the amount of additive genetic variance present in a particular trait. The amount of genetic variance determines the breeding and selection procedure for future genetic improvement. Heritability was estimated for six parities collectively. Binary and continuous estimates of heritability for various reproductive disorders has been presented in Table 2 .

Table 2: Heritability estimate for reproductive disorders

\begin{tabular}{ccc}
\hline Traits & $\begin{array}{c}\text { Heritability } \\
\text { (Continous) }\end{array}$ & Standard Error \\
\hline Dystocia & 0.04 & 0.020 \\
ROP & 0.10 & 0.003 \\
Anestrus & 0.05 & 0.001 \\
RB & 0.074 & 0.010 \\
PPAD & 0.121 & 0.020 \\
Abortion & 0.085 & 0.010 \\
\hline
\end{tabular}

The heritability estimates for dystocia, retention of placenta, anestrus, repeat breeding and abortion were found to be highly appreciable i.e. 0.04, 0.10, 0.05, 0.074 and 0.85 respectively. So while the heritability estimates for postpartum abnormal discharge has been 0.121 i.e. with $12 \%$ additive gene action. The estimates obtained for reproductive disorders were lower than reports of Tomar (1984) and Taraphder (2002) in Murrah buffaloes. Low heritability estimates were found in case of dystocia (0.05), abortion (0.11), still-birth (0.07) premature birth $(0.06)$ and retained placenta 0.15 while medium value of heritability was observed for prolapse and metritis $(0.25$ and 0.23$)$ by Taraphder (2002) in Murrah buffaloes. Higher heritability has been reported for various reproductive disorders in Karan swiss cows by Balasundaram (2008).

Therefore very low heritabilities indicate that the above reproductive disorders occurring in a small population of an organized farm are mainly governed by non- genetic factors. It means the incidence of above reproductive disorders can be reduced through better management.

\section{Breeding values of sires for reproductive disorders}

Breeding values of sires were estimated for reproductive disorder traits. The results have been shown in Table 3 . The rank correlations among various reproductive disorders traits have been given in Table 4 .

Table 3: Distribution of sires in different classes of breeding values for reproductive disorders

\begin{tabular}{cccc}
\hline \multirow{2}{*}{ Reproductive problem } & $\begin{array}{c}\text { Breeding } \\
\text { Value }\end{array}$ & \multicolumn{2}{c}{$\begin{array}{c}\text { Sires below herd } \\
\text { average }\end{array}$} \\
\cline { 2 - 4 } & Average (\%) & Number & \% \\
\hline Dystocia & 0.4 & 10 & 8 \\
Retention of placenta & 0.2 & 97 & 82 \\
Abortion & 0.4 & 79 & 67 \\
Anestrus & 0.2 & 48 & 40 \\
Repeat breeding & 7.8 & 68 & 58 \\
Postpartum abnormal & 11.8 & 68 & 58 \\
discharge & & & \\
\hline
\end{tabular}

Table 4: Rank correlation estimates for reproductive disorders

\begin{tabular}{|c|c|c|c|c|c|c|}
\hline & 胥 & 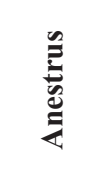 & 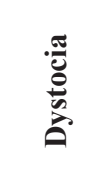 & 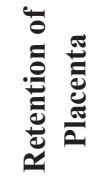 & 我 & 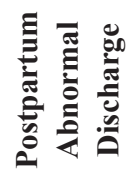 \\
\hline Abortion & 1 & $\begin{array}{c}0.98 \pm \\
0.03\end{array}$ & $\begin{array}{c}0.98 \pm \\
0.03\end{array}$ & $\begin{array}{c}0.99 \pm \\
0.02\end{array}$ & $\begin{array}{c}0.97 \pm \\
0.03\end{array}$ & $\begin{array}{c}0.95 \pm \\
0.04\end{array}$ \\
\hline Anoestrus & & 1 & $\begin{array}{c}0.99 \pm \\
0.02\end{array}$ & $\begin{array}{c}0.97 \pm \\
0.03\end{array}$ & $\begin{array}{c}0.98 \pm \\
0.02\end{array}$ & $\begin{array}{c}0.97 \pm \\
0.03\end{array}$ \\
\hline Dystocia & & & 1 & $\begin{array}{c}0.96 \pm \\
0.03\end{array}$ & $\begin{array}{c}0.98 \pm \\
0.02\end{array}$ & $\begin{array}{c}0.95 \pm \\
0.04\end{array}$ \\
\hline $\begin{array}{c}\text { Retention of } \\
\text { Placenta }\end{array}$ & & & & 1 & $\begin{array}{c}0.96 \pm \\
0.03\end{array}$ & $\begin{array}{c}0.94 \pm \\
0.04\end{array}$ \\
\hline Repeat Breeding & & & & & 1 & $\begin{array}{c}0.96 \pm \\
0.03\end{array}$ \\
\hline $\begin{array}{c}\text { Postpartum } \\
\text { Abnormal } \\
\text { Discharge }\end{array}$ & & & & & & 1 \\
\hline
\end{tabular}




\section{Breeding values of sires for reproductive traits}

The overall mean for breeding value for dystocia was $0.4 \%$ (Table 3 ). The research findings showed that $8 \%$ sires used in the herdfrom 2007 to 2018 had breeding values lower than the overall average of the herd. The results suggested that there is enough scope for improvement of dystocia. This suggested that selection of superior sires should be practiced to further reduce incidence of dystocia. Sharma (2010) reported that $71.43 \%$ primiparous and $81.06 \%$ pluriparous cows have breeding value below the herd average.

The overall means for breeding values for retention of placenta and abortion were 0.2 and $0.4 \%$, respectively (Table 3). Overall results indicated that 82 and 67 percent sires used in the herd had breeding values less than the herd average which was in desirable direction for these traits. The overall means for breeding values based on anestrus, RB and PPAD were $0.2,7.8$ and $11.8 \%$, respectively. About 40,58 and $58 \%$ sires had breeding values lower than the overall average of the herd for incidence of anestrus, RB and PPAD. About 48 sires had breeding values lower than $0.2 \%$, whereas another 70 had breeding values higher than $0.2 \%$ for anestrus. About 40, 58 and $58 \%$ sires had the breeding values lower than $0.2,7.8$ and 11.8 while 60,42 and 42 sires had the breeding values higher than $0.2,7.8$ and $11.8 \%$ for RB and PPAD. Sharma (2010) reported that 57.90 and $56.58 \%$ of sires have breeding values lower than herd averages for stillbirth and abortion in pluriparous cows; for anestrus about 66.66 and 50\% sires showed low breeding value than the herd average in primiparous and pluriparous cows.

\section{Rank correlation}

The present study had also carried out to examine if one reproductive problem had any association with other reproductive problem. Genetic correlation among reproductive disorders were high and significant. Rank correlation among different reproductive disorders have been given in Table 4 .

Rank correlation of abortion with other reproductive disorders was significantly high. Rank correlation of abortion with ROP was very high $(0.99 \pm 0.02)$ and with anestrus, dystocia, RB and PPAD were also high i.e. $0.98 \pm 0.03,0.98 \pm 0.03,0.97 \pm 0.03,0.95 \pm 0.04$ respectively. It means ranking of sires for those reproductive disorders were not different from those of abortion. In other words, sires evaluated for abortion on the basis of their progeny performance would give similar rankings as if sires had been assessed for more incidence of anestrus, dystocia, RB and PPAD condition in their daughters. Positive, moderate and significant correlation of abnormal calving (dystocia, abortion, $\mathrm{PB}$ and $\mathrm{SB}$ ) with prolapse, ROP and metritis ( $0.532,0.423$ and 0.373 respectively) was reported by Taraphder (2002) in Murrah buffaloes.

From rank correlation analysis it was analysed that correlation of anestrus with RB, ROP and PPAD were significantly high i.e. $0.98 \pm 0.02,0.97 \pm 0.03$ and $0.97 \pm 0.03$ respectively. But rank correlation between anstrus and dystocia was very high $(0.99 \pm 0.02)$. However, for anestrus the rank correlations was significant and high magnitude thereby indicating that ranking of sires for anestrus was dependent of ranking of sires for other reproductive disorders like RB, ROP and PPAD. Taraphder (2002) found that in Murrah buffalo rank correlation of anestrus with abnormal calving, uterovaginal and udder problems were low and non-significant.

Rank correlation was significant for dystocia with ROP, $\mathrm{RB}$ and PPAD. Correlation between dystocia, ROP, RB and PPAD were $0.96 \pm 0.03,0.98 \pm 0.02$ and $0.95 \pm 0.04$ respectively. This indicated that the selection of sire for reduced incidence of dystocia will make improvement for ROP, RB and PPAD also. Taraphder (2002) reported that rank correlation of abnormal calving (dystocia, abortion, premature birth and stillbirth) with retention of placenta was positive, moderate $(0.423)$ and significant in Murrah buffaloes.

Significant effect of retention of placenta with RB and PPAD for rank correlation has been found. Rank correlation between ROP with RB and PPAD were $0.96 \pm 0.03$ and $0.94 \pm 0.04$ respectively. It means the improvement in these traits can bring improvement in ROP. The results indicated that the sires ranking lower were those which also had higher incidence of these reproductive disorders in their progeny. Low (0.270) and non-significant correlation of anestrus with retention of placenta was reported by Taraphder (2002) in Murrah buffaloes.

Rank correlation between RB and PPAD was significant and of high magnitude $(0.96 \pm 0.03)$. This indicated that progeny of sires had more chances of repeat breeding also had more chances of postpartum abnormal discharge. 
If there is any association between two disorders (rank correlation for two reproductive problems is high) then it means, the sire containing the gene for first reproductive disorder, also contain the gene for other correlated problem. Due to which in daughters of that sire if one reproductive problem is high then the chances of other correlated problem will be high.

\section{CONCLUSION}

Heritability estimates of reproductive problems have indicated appreciable values, signifying that incorporation of these traits in selection program will enhance the rate of improvement.

\section{REFERENCES}

Asdel, S.A. 1951. Variation in amount of culling from DHIA herd. J. Dairy Sci., 34: 52.

Balasundaram, B. 2008. Influence of Genetic and non-genetic factors on incidence of reproduction disorders in Karan Fries cows. Thesis. NDRI, Karnal.

DADHF. 2012. 19 $9^{\text {th }}$ Livestock Census, Department of Animal Husbandry, Dairying and Fisheries, Ministry of Agriculture. Government of India.

DADHF. 2017. Basic animal husbandry and fisheries statistics, Department of Animal Husbandry, Dairying and Fisheries, Ministry of Agriculture. Government of India.

Datta, S. 1951. Problem of FMD in India. Indian Vet. J., 27: 403.

Gilmore, J.A. and McDaniel, B.T. 1977. Health costs of dairy cattle, its variation and its associations with milk yield and type scores. J. Dairy Sci., 60(1): 76.
Hut, F.B. 1958. Genetic resistance to disease in domestic animals. Cornell University press, Ithaca, New York.

Khan, H.M., Bhakat, M., Mohanty, T.K., Raina, V.S. and Gupta, A.K. 2011. Effect of non-genetic factors on reproductive disorders in Murrah buffaloes. Buffalo Bulletin, 30(2): 120$125+147$.

Robertson, A. and Lerner, M. 1949. The heritability of all or none traits: viability of poultry. Genetics, 34(4): 395-411.

Shanks, R.D., Freeman, A.E. and Dickinson, F.N. 1981. Postpartum distribution of costs and disorders of health. $J$. Dairy Sci., 64(4): 683-688.

Sharma, P.K. 2010. Genetic evaluation of Karan Fries cows for functional traits. Ph.D. Thesis, NDRI, Karnal.

Steel, R.H.D. and Torrie, J.H. 1960. Principles and Procedures of Statistics with special reference to the Biological Sciences. MacGraw Hill Company, New York.

Singh, N.K. 2015. Modelling lactation curve in Murrah buffaloes using monthly test day milk yields. Thesis. Sardar Vallabhbhai Patel University of Agriculture and Technology, Meerut (U.P.).

Taraphder, S. 2002. Genetic and economic evaluation of Murrah buffaloes for lactation disorders and disposal pattern. Ph.D. Thesis, NDRI, Karnal.

Tomar, S.S. 1984. Inheritance of certain threshold characters in buffaloes. Ph.D. Thesis submitted to Kurukshetra University, Kurukshetra Haryana. 